\title{
A new empirical model for estimating the hydraulic conductivity of low permeability media
}

\author{
SHIPENG QI, ZHONGHUI WEN, CHENGPENG LU, LONGCANG SHU, \\ JIANWEI SHAO, YIN HUANG, SHUO ZHANG \& YIXIN HUANG \\ College of Hydrology and Water Resources, Hohai University, Nanjing, 210098, China \\ luchengpeng@hhu.edu.cn
}

\begin{abstract}
Hydraulic conductivity $(K)$ is one of the significant soil characteristics in terms of flow movement and solute transport. It has been recognized that $K$ is statistically related to the grain-size distribution. Numerous models have been developed to reveal the relationship between $K$ and the grain-size distribution of soil, but most of these are inappropriate for fine-grained media. Therefore, a new empirical model for estimating $K$ of low permeability media was proposed in this study. In total, the values of $K$ of 30 soil samples collected in the Jiangning District of Nanjing were measured using the single-ring infiltrometer method. The new model was developed using the percentages of sand, silt and clay-sized particles, and the first and the second rank moment of the grain-size through the moment method as predictor variables. Multivariate nonlinear regression analysis yielded a coefficient of determination $\left(R^{2}\right)$ of 0.75 , indicating that this empirical model seems to provide a new approach for the indirect determination of hydraulic conductivity of low permeability media.
\end{abstract}

Key words hydraulic conductivity; empirical model; grain-size analysis; fine medium

\section{INTRODUCTION}

The hydraulic conductivity $(K)$ of soil is of great significance in hydrogeology. All the development, management and protection of groundwater and the prediction of contaminant transport need reliable estimates of $K$.

Hydrogeologists have searched for reliable techniques to determine the $K$ of soils, for better groundwater development, management and conservation. Many different techniques have been presented, including field methods, laboratory methods and empirical formulae. However, precise estimation of $K$ by field techniques is limited by the lack of accurate information of the aquifer geometry and hydraulic boundaries and always prohibited by the high cost for the construction of observation wells (Chen et al. 2010). Laboratory tests, on the other hand, present formidable problems in the sense of obtaining representative samples. It has long been recognized that $K$ is statistically related to the grain-size distribution of granular porous media. As a result, numerous models estimating $K$ from empirical formulae based on grain-size distribution, have been developed and used to overcome these problems. Grain-size methods are less expensive and do not depend on the geometry and hydraulic boundaries of the aquifer. Most significantly, information about the textural properties of soils is easy to obtain. Consequently, groundwater professionals have tried for decades to reveal the correlation between $K$ and the grain-size distribution of soil. The tasks appear rather straight forward, but it is found that this correlation is not easily established (Pinder and Celia 2006).

So far, many predictive methods have been revealed to estimate the $K$ from grain-size analysis which use the analogy of pipe flow and flow in capillaries to represent water flow in soil (Kozeny 1927; Carmen 1937, 1956). Besides these methods, empirical formulae have also been developed (Hazen 1892; Krumbein and Monk 1942). A popularly accepted relationship was proposed by Hazen (1892) with the form:

$$
K=A d_{10}^{2}
$$

where $K$ is hydraulic conductivity $(\mathrm{cm} / \mathrm{s}) ; A$ is a constant; and $d_{10}$ is the effective diameter. In order to explain the distribution of the grain-size curve, Masch and Denny (1966) replaced the effective diameter with the median grain size $d_{50}$ as the representative size in an attempt to correlate $K$ to grain-size. Krumbein and Monk (1942) calculated $K$ of unconsolidated sands with an empirical model of the form: 


$$
K=\left(760 d_{w}^{2}\right) \exp \left(-1.31 \sigma_{\varphi}\right)
$$

where $d_{w}$ is geometric mean diameter (in weight) in millimetres; and $\sigma_{\varphi}$ is standard deviation of the $\varphi$ distribution function ( $\varphi=-\log _{2} d$, for $d$ in $\mathrm{mm}$ ).

The hydraulically-based Kozeny-Carmen equation is one of the most widely accepted and used empirical models. It was originally proposed by Kozeny (1927) and modified by Carmen $(1937,1956)$ to become the Kozeny-Carmen equation:

$$
K=\left(\frac{\rho_{w} g}{\mu}\right) \frac{\varphi^{3}}{(1-\varphi)^{2}}\left(\frac{d_{m}^{2}}{180}\right)
$$

where $\rho_{w}$ is fluid density; $\mu$ is fluid viscosity; $\varphi$ is porosity; and $d_{m}$ is representative grain size. The problem of this equation is that the choice of the representative grain size is critical to the successful prediction of $K$. Carrier (2003) noted that the model is not appropriate for either soil with an effective size $>3 \mathrm{~mm}$ or for clayey soils.

Puckett et al. (1985) proposed a model and used the percent of clay-sized particles as the predictive variables of $K$ :

$$
K=4.66 \times 10^{-3} \exp (-0.1975 C)
$$

where $C$ is the clay-sized particles (\%) in the soil sample. In addition, Jabro (1992) estimated $K$ from bulk density and grain-size and developed the following model:

$$
\log \left(K_{s}\right)=9.59-0.81 \log S i-1.09 \log C-4.64 B d
$$

where $S i$ is the percentage of silt-sized particles; $K_{s}$ is hydraulic conductivity $(\mathrm{cm} / \mathrm{h}) ; B d$ is the soil bulk density $\left(\mathrm{g} / \mathrm{cm}^{3}\right)$.

The foregoing discussion shows clearly that the value of $K$ significantly depends on the grainsize distribution and the percentage of the representative particles. Although many predictive and empirical models have been proposed in the past decades, models for fine media are scarce and a general correlation between $K$ and the sorting condition integrating a wide range of soil is not yet available. The objective of this paper is to develop a new model which can estimate $K$ of fine media quickly and easily, using unique representations of the grain-size distribution of soils. The new model was developed using the percentages of sand $(\mathrm{Sa})$, silt $(\mathrm{Si})$ and clay $(\mathrm{C})$ sized particles, and the first and the second rank moment of the grain-size through the moment method as predictor variables. All the parameters are combined and used to predict $K$ using multivariate nonlinear regression analysis.

\section{MATERIALS AND METHODS}

\subsection{In situ permeameter test}

The study area is located in the central Jiangning District of Nanjing, lying on the south bank of the downstream of Yangtze River, between $118^{\circ} 31^{\prime} \mathrm{E}-119^{\circ} 04^{\prime} \mathrm{E}$ and $30^{\circ} 38^{\prime} \mathrm{N}-32^{\circ} 13^{\prime} \mathrm{N}$ with an area about $329 \mathrm{~km}^{2}$ (Fig. 1). This area lies over a sedimentary fluvial aquifer consisting mainly of gravel, sand, silt, and clay sediments. The climate is wet and warm, and the average annual temperature is $15.5^{\circ} \mathrm{C}$ and average annual precipitation is $1045 \mathrm{~mm}$. Thirty investigation sites were selected and the sediments consisted largely of silt and sand, with a small amount of clay.

The falling-head standpipe infiltration test, as described by Nestingen (2007), Lu (2011) and Cheng et al. (2011), were conducted to estimate $K$. A stainless steel cutting ring, $15.0 \mathrm{~cm}$ in length and $10.0 \mathrm{~cm}$ in diameter, was pressed vertically into the soil to a depth of around $5-7 \mathrm{~cm}$, with the vegetation stratum removed before the test. Then, water was added from the top opening of the cutting ring and hydraulic conductivity head measurements were recorded over a time period and a column of soil was collected after the test. The soil moisture content also needs to be measured before and after the test. The derivation of $K$ complied with the procedure proposed in Lu (2011). 


\subsection{Soil sampling and grain-size analysis}

At each site, once the permeameter test was completed, a soil sample was collected and placed into a sampling bag and then all the samples were sent to the State Key Laboratory of HydrologyWater Resources and Hydraulic Engineering for grain-size analysis. The grain-size analyses were conducted in laboratory using a Saturn DigiSizer, which can provide detailed information on the grain-size distribution. Compared to traditional methods, more comprehensive properties of samples can be obtained. All the operations complied with the River Sediment Grain Size Analysis Procedures (SL 42-92). According to the International Textural Grade, particle size less than $0.002 \mathrm{~mm}$ is grouped into clay, $0.002-0.02 \mathrm{~mm}$ is grouped as silt, and $0.02-2.0 \mathrm{~mm}$ is grouped as sand. In this paper, we recommend the moment method to calculate the feature parameter of the grain-size distribution. The first rank moment $(X)$ is a measure of the mean diameter of the distribution and the second rank moment $(\delta)$ is a measure of the diffusion of the distribution and reflects the sorting condition of the sediment.

\subsection{Regression model}

A regression model was developed to predict $K$ using the obtained parameters as the predictor variables (the \% of $S a, S i$ and $C$-sized particles, and the first and the second rank moment). The regression model correlates the value of $K$ to the predictor variables:

$$
K=\alpha_{1} \exp \left(\beta_{1} x_{1}\right)+\alpha_{2} \exp \left(\beta_{2} x_{2}\right)+\alpha_{3} \exp \left(\beta_{3} x_{3}\right)+\alpha_{4} x_{4}^{\beta_{4}}+\alpha_{5} x_{5}^{\beta_{5}}
$$

where $K$ is computed hydraulic conductivity; and $\alpha_{i}, \beta_{i}$ are coefficients determined by the regression analysis ( $i=1$ to 5 ); and $x_{i}$ is the value of the predictor variables. Based on what has been discussed, it can be concluded that the predictor variables are relevant to $K$. Accordingly, all of them are used in the regression analysis.

The reliability and accuracy of the model can be answered by using: (1) the coefficient of determination $R^{2}$; and (2) the standard error of estimate $S_{e}$. The coefficient of determination $R^{2}$ equals the probability that the variance can be explained by the predictor variables. Thus, $R^{2}$ is an indicator of accuracy. The magnitude of $S_{e}$ is a physical indicator of the error between the computed and measured values.

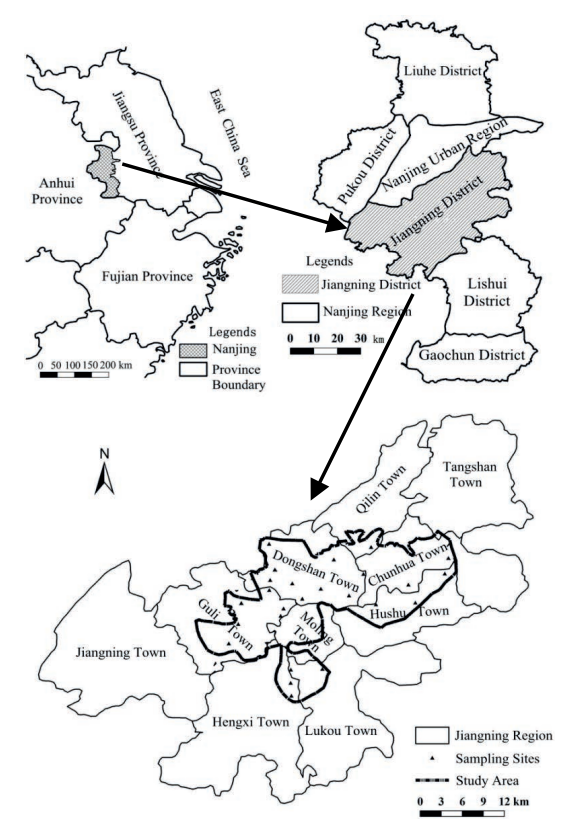

Fig. 1 Locations of the study area and the experiment sites. 


\section{RESULTS AND DISCUSSION}

\subsection{Graphical analysis}

Plots of $K$ versus the proposed variables, the percentages of sand, silt and clay-sized particles, and the first and the second rank moments were statistically analysed for increasing or decreasing trends. All the trends were estimated for significance using the $F$-statistic (Draper and Smith, 1981). Trends with higher significance have a higher value of $F$. The significance level at $\alpha_{\text {fail }}$ is an index of the significance of the trends. The significance increases as the value of $\alpha_{\text {fail }}$ decreases.

Figure 2(a)-(c) shows $K$ respectively as a function of the percent of clay, silt and sand-sized particles of the grain-size distribution, respectively. Two different trends can be observed, in which $K$ increases with an increase in the percent of clay and silt, while an inverse trend is observed between $K$ and the percent of sand-sized particles. Intuitively, this conclusion is irrational. Soils having a higher quantity of fines and clay, generally have lower hydraulic conductivity. But a counter conclusion, consistent with this paper, was obtained by Craig et al. (1995) and Boadu (2000). A positive coefficient is present for clay content and percent of fines, in their regression model which indicates that hydraulic conductivity increases with increasing clay content and fines. Increasing clay content, while maintaining a constant plasticity index, indicates that the clay fraction is composed of less active minerals, and results in higher hydraulic conductivity (Craig et al., 1995). Sometimes, for coarse content, the correlation between $K$ and the gravel content is likely to be inversely proportional on a local scale. When increasing the quantity of gravel content in sand-clay soil causes an increase in soil resistivity, it will also result in $K$ decreasing (Shevnin, et al. 2006). Based on what have been discussed, the phenomenon observed in Fig. 2 can be well explained.

To confirm the significance of the trends, the values of measured $K$ were regressed linearly on the percent of $C, S i$ and $S a$-sized particles. The $F$-statistics were $F=41.71,33.50,32.17$, respectively, and $\alpha_{\text {fail }}=2.4 \mathrm{E}-8,3.0 \mathrm{E}-7,4.7 \mathrm{E}-7$ (less than 0.01 ). The outcomes of the $F$-statistics substantiate that the trends are significant at the level of 0.05 .

Plots of $K$ as a function of the first and the second rank moment, respectively, are shown in Fig. 2(d) and (e). An inverse trend between $K$ and the first and the second rank moments is clear. The $F$-statistics $\left(F=7.35,27.64, \alpha_{\text {fail }}<0.01\right)$ indicate that the trend between the two variables and $K$ is significant at the 0.05 level.

\subsection{Hydraulic conductivity prediction}

Although the relationship between $K$ and the five parameters is not very strong, integrating them into a multivariate system and implementing a multivariate regression analysis may substantially improve the relations (Draper and Smith, 1981). Consequently, the multivariate regression model can increase the reliability and accuracy of the prediction. The regression model which best correlates $K$ to the predictors is:

$$
\begin{aligned}
K= & 1.09 \times 10^{-11} \exp (184.7 C)+8.31 \times 10^{-9} \exp (39.33 \mathrm{Si})+ \\
& 1.61 \times 10^{7} \exp (-71.18 \mathrm{Sa})+0.05 X^{-1.11}+0.006 \delta^{-0.74}
\end{aligned}
$$

This equation describes a model which estimates $K$ of fine media using information obtained from the grain-size distribution. The model is expressed by a functional relation between $K$ and a set of five parameters. $R^{2}$ is 0.75 , implying $75 \%$ of the variance in $K$ can be explained by the model.

The reliability of the model was assessed by comparing outputs calculated from it with the measured values, and computing the correlation coefficient and the standard error of the estimation (Fig. 3). The correlation coefficient at $95 \%$ confidence interval is $0.87\left(R^{2}=0.75\right)$, the standard error of estimate $\left(S_{e}\right)$ is 2.13 (less than the mean value of $K$ ), and the root-mean-square error is 1.54. These indicators are statistically significant, indicating that the measured values and the predicted values are comparable. Figure 3 shows that the estimated values with multi-variations do not agree well with the in situ observations; this may be due to many other factors which relate to the values of $K$, such as the soil bulk density, the soil moisture content and the compacted 

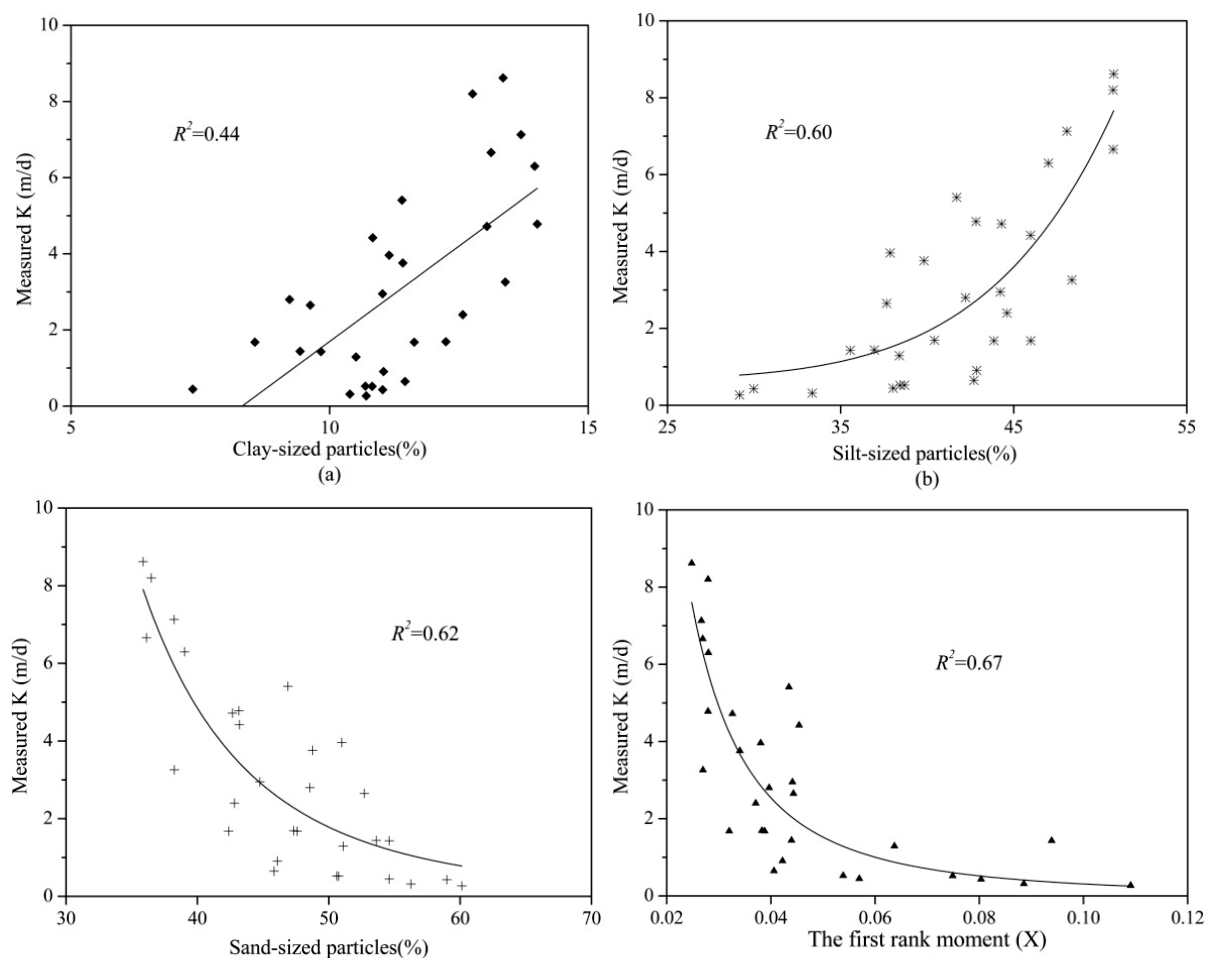

(d)

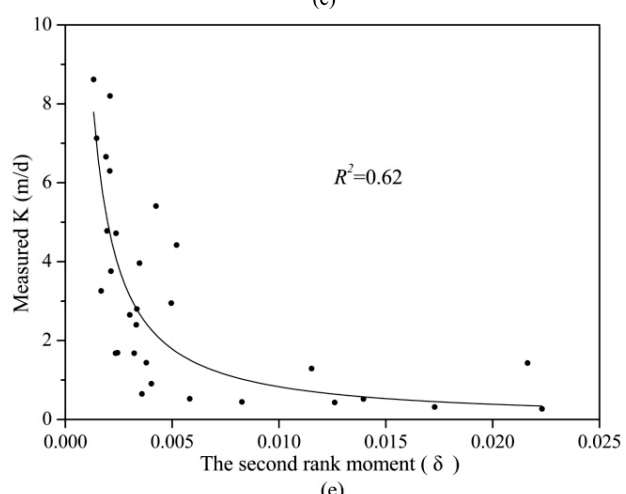

Fig. 2 Plots of the relationship between hydraulic conductivity and the five predictor variables of grainsize distribution.

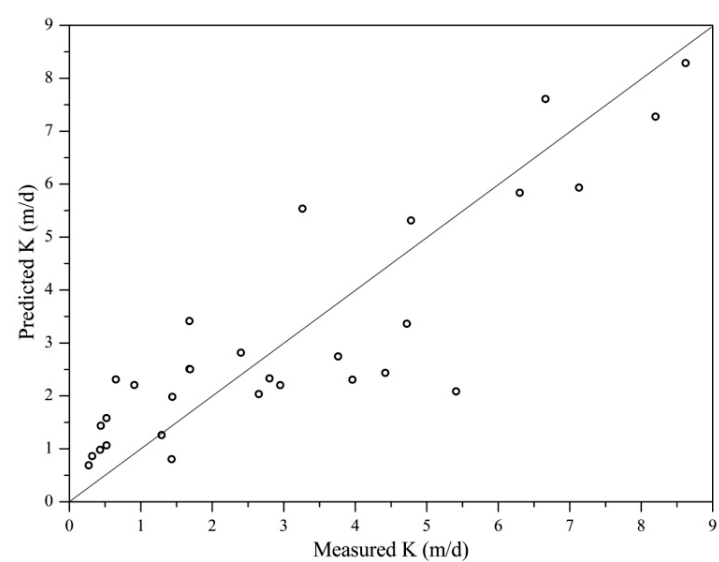

Fig. 3 Plot of measured hydraulic conductivity $K_{m}$ versus predicted values $K_{p}$ using established regression model (straight line represents line of perfect quality). 
condition, etc., that were not considered in this study. If more factors are taken into account, the accuracy of the model and the fitting of the measured $K$ and the predicted $K$ could be improved.

\section{SUMMARY AND CONCLUSIONS}

According to the previous research, estimation of $K$ from measured soil textural properties is a rational alternative to the field and experimental methods. In this paper, an empirical model is proposed to estimate $K$ of soils from grain-size distribution. The new model was based on multivariate nonlinear regression analysis and its results are reliable and explain the whole spectrum of grain-size distribution via the percentages of sand, silt and clay-sized particles, and the first and the second rank moment of the grain-size through the moment method. The main achievement of this research is the incorporation of the first and the second rank moment of the grain-size distribution as characteristic parameters of grain-size in the new model for determining the value of $K$.

The new empirical model is deemed to be a rational substitute to experimental methods. Its superiority will be highlighted when the preparation of the field experiment is difficult. In certain cases, it may also be applied to provide first-hand information about hydraulic properties in a field environment, such as the estimated values of $K$ where field operations are prohibited by some physical factors.

Acknowledgements This research was supported by National Natural Science Foundation of China grants (41201029), China Postdoctoral Science Foundation (2013M540410), and the Fund of the Assessment of the Environment Impact of Groundwater in Jiangning District. The authors would like to express thanks to the State Key Laboratory of Hydrology-Water Resources and Hydraulic Engineering in the sampling and laboratory work.

\section{REFERENCES}

Boadu, F.K. (2000) Hydraulic conductivity of soils from grain-size distribution: new models. Journal of Geotechnical and Geoenvironmental Engineering 126, 739-746.

Carman, P.C. (1937) Fluid flow through granular beds. Transactions of the Institute of Chemical Engineers $15,150$.

Carman, P.C. (1956) Flow of gases through porous media. Butterworths Scientific Publications, London.

Carrier, W.D. (2003) Goodbye, Hazen. Hello, Kozeny-Carman. Journal of Geotechnical and Geoenvironmental Engineering 1054.

Chen, X., et al. (2010) Spatial variability of specific yield and vertical hydraulic conductivity in a highly permeable alluvial aquifer. Journal of Hydrology 388, 379-388.

Cheng, Q., et al. (2011) Water infiltration underneath single-ring permeameters and hydraulic conductivity determination. Journal of Hydrology 398, 135-143.

Craig, H., et al., (1995) Hydraulic conductivity of thirteen compacted clays. Clay and Clay Minerals 43(6), 669-681.

Draper, N., and Smith, H. (1981) Applied regression analysis, Wiley, New York.

Hazen, A. (1892) Some physical properties of sands and gravels, with special reference to their use in filtration. $24^{\text {th }}$ Annual Report, Massachusetts State Board of Health, Pub. Doc. 34, 539-556.

Jobro, J.D. (1992) Estimation of hydraulic conductivity of soils from particle size distribution and bulk density data. Journal of the American Society of Agricultural Engineers, 35(2), 557-560.

Kozeny, J. (1927) Uber kapillare Leitung des Wassers in Boden. Sitzungsber Akad. Wiss. Wien Math. Naturwiss Kl., Abt. 2a, 136, 271-306 (in German).

Krumbein, W.C. and Monk, G.D. (1942) Permeability as a function of the size parameters of unconsolidated sand. Transactions of the American Institute of Mining and Metallurgical Engineering 151, 13-63.

Lu. Chengpeng, (2011) Study on the identification of the heterogeneity of aquifers-taking karst aquifer and hyporheic zone as examples. Hohai University, Nanjing.

Masch, F.D. and Denny, K.T. (1966) Grain-size distribution and its effect on the permeability of unconsolidated sands. Water Resource Research 2, 665-677.

Nestingen, R., (2007) The Comparison of Infiltration Devices and Modification of the Philip-Dunne Permeameter for the Assessment of Rain Gardens. University of Minnesota, Minnesota.

Pinder, G.F. and Celia, M.A. (2006) Subsurface Hydrology. John Wiley \& Sons Interscience, Hoboken, New Jercy.

Puckett, W.E., et al. (1985) Physical and mineralogical data to determine soil hydraulic properties. Soil Science Society of America Journal, 49(4) 831-836.

Shevnin, V., et al. (2006) Estimation of hydraulic conductivity on clay content in soil determined from resistivity data. Geofisica Internacional 45(3), 195-207.

Todd, D.K. and Mays, L.W. (2005) Groundwater Hydrology. John Wiley \& Sons, New York. 